\title{
Searle's Speech Act Theory: An Integrative Appraisal
}

\author{
Acheoah, John Emike \\ Department of European Languages, Faculty of Arts, Management and Social Sciences, \\ Federal University, Birnin-kebbi, Nigeria \\ Email:actualemike@gmail.com
}

Abstract: This paper is an integrative appraisal of Searle's speech act theory. The nature of speech acts makes them worthy of scholarly attention. Most speech acts are focused and directed as they are encoded by the speaker and decoded by the hearer. They are intended to have a certain point, and they are intended to be understood as such. This investigation explores Lawal's Communicative Model Theory and Acheoah's Pragma-crafting Theory to contend for a vibrant, all-encompassing speech act theory and establish the strengths and weaknesses of Searle's speech act theory. This study finds that: the notions "speaker's intention" and "linguistic convention" mentioned in Searle's speech act theory are loosely used. Context-phenomenon is not extensively discussed in Searle's theory in which speakers' intention is the core. Without a context-sensitive, integrative theoretical framework, the investigation of the contextual nuances which determine the use and interpretation of language remains a futile endeavour. Like Austin's speech act theory, Searle's speech act theory strongly recommends "linguistic conventions" for the performance of speech acts at the expense of a wide range of discourse constraints.

Keywords: Pragmatic theories, Searle's speech act theory, the Pragma-crafting Theory, Communicative Model Theory, appraisal of Searle's speech act theory

\section{INTRODUCTION}

This paper investigates the strengths and weaknesses of Searle's speech act theory through an integrative discourse; it is an investigation that is hinged on two theoretical frameworks in language study.

Pragmatics is relevant to various disciplines with a stake on how utterances are understood. Even when there are underlying universals of usage, there is considerable room for context-driven use of communication elements. The literature shows that classical and contemporary speech act theories neither adequately explain nor capture the complexities of natural communication.

\section{SEARLE'S SPEECH ACT THEORY}

Searle's seminal book was titled Speech Acts: An Essay in the Philosophy of Language. It was developed in subsequent works such as Searle (1969), and it was a speech act proposal. Like Austin, Searle distinguishes "illocutionary acts" which he regards as the "complete" speech acts, from "perlocutionary acts" which concern the consequences or effects of illocutionary acts on hearers. He further distinguishes "utterance acts" (the act of uttering words, which Austin calls "Phatic Acts") from "propositional acts", which are used to refer and predicate. But Searle disagrees with Austin's distinction between locutionary and illocutionary acts (cf. Searle 1969:22-25).

Searle classifies rules into regulative rules and constitutive rules. Regulative rules he says, regulate antecedently or independently, existing forms of behavior. These rules operate as imperatives and constitute the basis of appraising behavior. They have the feature "Do x" or "If Y, do x". Examples of such rules are rules of etiquette 
which govern interpersonal relationships existing independently of the rules. Constitutive rules, on the other hand, transcend mere regulatory function as they incorporate and explain new behavioral patterns. They constitute and regulate an activity whose existence is logically dependent on the rules. They may also have the form "Do X" or "If Y, do X" but some have the form "X counts as Y in the context C" (cf. Searle 1969:34-35). They are traditionally part of a given system. For example, obeying the rules of cooking a particular diet presupposes doing the actual act of cooking.

Searle's speech act taxonomy is an attempt to refine Austin's and this taxonomy is based on "illocutionary point", "direction-of-fit" and "sincerity conditions" (as well as other features including the role of authority, discourse relations, etc.). See Searle (1969) for tips on this). By "illocutionary point", Searle means the "purpose" of the speech act in question. The second criterion (direction-of-fit) concerns the match between our words and the world. While some speech acts try to get the words (or, more specifically, their propositional content) to match the world, others try to get the world to match the words. Assertions for example, try to get our words to match the world while promises and requests try to get the world to match our words. Searle represents the word-to-world direction-of-fit with a downward arrow and the world- to-word direction-of-fit with an upward arrow. He notes that direction-of-fit is always a consequence of illocutionary point.

A third major criterion concerns differences in the psychological states expressed. Thus, a person who "states, explains, asserts, or claims that $\mathrm{P}$ expresses the belief that $\mathrm{P}$; a man who promises, vows, threatens, or pledges to do A expresses a desire (want, wish) that $\mathrm{H}$ do $\mathrm{A}$; a man who apologizes for doing A expresses regret at having done A; etc." The psychological state expressed in the performance of a speech act is therefore the "sincerity condition" of the act. Apart from these three major criteria, which Searle considers the most important, he also examines other important aspects of a speech act in his taxonomy. These include the role of authority, discourse relations, the force or strength with which the illocutionary force is presented, differences in the status of speaker and hearer, differences in the way the utterance relates to the interests of the speaker and hearer, differences between acts that are always speech acts and those that can be but need not be performed as speech acts, differences between acts that require extra-linguistic institutions for their performance and those that do not.

Like Austin, Searle comes up with five categories of illocutionary acts: Assertives, Directives, Commissives, Expressives and Declarations. According to him, "the point or purpose of the members of the Assertive class is to commit the speaker (in varying degrees) to something's being the case, to the truth of the expressed proposition. The direction-of-fit is one in which we try to fit our words to the world and the psychological state expressed is "belief that p". The simplest test for an Assertive is that it can literally be characterized as true or false. Examples of verbs denoting Assertives include boast, conclude, deduce, etc. This class accommodates most of Austin's Expositives and many of his Verdictives.

In Searle's second category (Directives), the illocutionary point consists in the fact that "they are attempts ... to get the hearer to do something." The direction-of-fit is world-to-words, which means that the speaker tries to get the reality of the world to conform to his words. The sincerity condition is "want" (or wish or desire) and its propositional content is "that the Hearer $(\mathrm{H})$ will perform some future action A".

Examples of verbs denoting members of this category are ask, order, command, request, beg, pray, entreat, invite and advise. Many of Austin's Behabitives and Exercitives fall into this category.

Searle retains Austin's definition for his third category of speech acts (Commissives).

Verbs denoting Expressives include condole, deplore, welcome, congratulate. 
Declarations, according to Searle, are acts in which "the successful performance of one of its members brings about the correspondence between the propositional content and reality; successful performance guarantees that propositional content corresponds to the world". In order that Declarations be successfully performed, extra-linguistic institutions are involved, and there are rules which are "constitutive" of the speech act, unlike in supernatural Declarations such as when God says "Let there be light," and Declarations concerning language, itself such as I define, I name, I call etc. (Searle 1969:18). Declarations are symbolically represented thus:

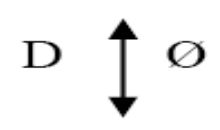

As the arrow indicates, the direction-of-fit is both words-to-world and world-to-words. The null symbol represents the fact that Declarations have no sincerity condition. The deep structure of Declarations is represented as follows (cf. Searle 1969:26):

I Verb NP + NP be pred

I/we (hereby) declare + state of war exists

Some institutions require Assertive claims to be made with the force of Declarations, and this is why Searle comes up with a class of Assertive Declarations, which, unlike Declarations, share with Assertives a sincerity condition. Examples are "I nominate you," I fire you," etc.

\section{Crucial Postulations in Searle's Theory}

This study examines the following crucial postulations in Searle's speech act theory:

(Sa.) Speaking a language is performing acts intentionally according to conventional rules;

(Sb) Speech act is the core of communication;

(Sc.) Whatever can be meant can be said (the Principle of Expressibility);

(Sd.) There is a series of analytical connections between the notion of speech acts, what the speaker means, what the speaker intends, what the hearer understands, and what the rules governing the linguistic elements are;

(Se.) Crucial components of human communication include: discourse relations, the force or strength with which an illocutionary force is performed, differences in the status of speakers and hearer, differences in the way an utterance relates to the interests of the speaker and hearer, relations with extra-linguistic conventions, illocutionary point, direction of fit and sincerity condition.

\section{THEORETICAL FRAMEWORK}

The appraisal done in this study hinges on a two-fold theoretical framework: Lawal's (2012) Communicative Model Theory and Acheoah's (2015) Pragma-crafting Theory.

\section{The Communicative Model Theory}

Lawal (2012) posits that the Communicative Model Theory is eclectic in nature because it is the totality of the submissions of predating theories. The theory explains the interaction between message and medium through socio-linguistic and rhetorical devises. Elements in the theory include: 


\section{SPEAKER OR WRITER;}

2. MESSAGE (i.e.) writer's or speaker's impression in the form of ideas, beliefs, knowledge, feelings and attitudes, etc. on the one hand, or listener's or reader's impression decoded in the form of ideas, beliefs, knowledge, feelings, etc. on the other hand;

3. MEDIUM i.e. writer's or speaker's expression encoded in the form of: (i) A rhetorical mode (the primary stylistic device which incorporates linguistic norms and directs pragmatic interpretation of textual properties);

(ii) Linguistic "norms", constants, variants, and deviants.

\section{The Pragma-crafting Theory}

Acheoah's Pragma-crafting Theory is anchored by the following theoretical notions:

(i) P-crafting: It is a two-fold umbrella term: it comprises Event and Text.

(ii) Event: The participants of discourse (interactive and non-interactive participants) constitute Event. While the interactive participants perform linguistic, extra-linguistic and psychological acts, the non-interactive participants do not, and even if they do, their acts are always unconnected to the communication at hand; see Acheoah (2014a) where the label, $\mathrm{H}_{2}$, is used to refer to participants who are present in discourse, but are not speakers' interlocutors.

(iii) Text: Text captures the trio: Setting, Theme and P-crafting Features. "P-crafting Features" is a concept which has discrete theoretical notions demonstrated by the interactive participants in three different frames: linguistic acts, extra-linguistic acts and psychological acts.

(iv) Interactive participants: These are participants who make linguistic, extra-linguistic and psychological contributions to a communication event.

(v) Non-interactive participants: Although present in a communication event, the non-interactive participants do not make verbal or non-verbal contributions that concern the communication event.

(vi) Setting: This is the physical place in which a communicative event takes place as can be ascertained from pragmatic or linguistic data.

(vii) Theme: It is the message in Text as worked out by P-crafting Features.

(viii) P-crafting Features: The features which enable participants of discourse to "p-craft" include: Indexicals (INDXLs), Shared Macro-knowledge (SMK), Shared Contextual Knowledge (SCK), Shared Knowledge of Emergent Context (SKEC), Geoimplicatures (GIs), Linguistic Implicatures (LIs), Behavioural Implicatures (BIs), Contextual Presuppositions (CPs), Pragmadeviants (PDs), Object Referred (OR) and Operative Language (OL). It is necessary to understand these concepts:

a) Inference (INFR) has to do with making logical conclusions from available contextual data.

b) Indexicals (INDXLs) include demonstratives, first and second person pronouns, tense, specific time and place adverbs like now and here, and a variety of other grammatical features tied directly to the circumstances of utterance (Levinson 1983:54).

c) Shared Macro-knowledge (SMK) is the totality of what the participants of discourse understand as states-ofaffairs in the larger society, rather than in their immediate society.

d) Shared Contextual Knowledge (SCK) is background knowledge of participants in the physical context of communication. 
e) Emergent Context (EC) is any situation that suddenly emerges in an on-going discourse, and can impinge on illocutionary and perlocutionary acts.

d) Geoimplicatures (GIs) was coined from "geographical" and "implicature" to refer to practices that have geographical restriction in terms of people, and not just in terms of physical boundaries; physical relocation does not remove the meanings from the psyche of the natives of that region where such meanings operate as OR in OL.

e) Linguistic Implicature (LI) are meanings implied through linguistic elements (language) of Text.

f) Behavioural Implicature (BI) are meanings implied through extra-linguistic and psychological acts.

g) Contextual Presuppositions (CP) are products of Shared Contextual Knowledge (SCK); in a specific (micro-context) physical context of discourse, participants deduce meanings from verbal and non-verbal data limited to the participants themselves. The meanings deduced are treated as background assumptions (BAs) which direct interlocutory roles. Decoders (DCs) imply that Encoders (ENCs) understand that certain Verbal Elements (VEs) and Non-verbal Elements (NVEs) are deduced or infered as Object Referred (OR) in Operative Language (OL).

h) Linguistic Acts: These include: speech acts (direct, indirect and Pragmadeviants); supra-segmental features (stress, intonation, rhythm, pitch); phones (Ssss, Shhh, Mmmm, Ehmnn); Exclamations (Wao!, Oh!, Ah!, Abah!); and lyrical music. Due to space constraints, these concepts as well as others cannot be elaborately explained in this study. However, the concept, "phones", refers to speech features between the phoneme and the word. They are common components in both written and spoken discourses. Small as they are, they express emotions of various kinds besides having illocutionary potentials in context.

i) Extra-linguistic Acts: Extra-linguistic acts include: sociolinguistic variables (age, cultural background, social status/class, gender, relationship); non-lyrical music, drumming as well as semiotic particulars (weather, time, contextual object, colour, clothing, posture, perfume, location/position, size, body mark and silence), laughter, body movement).

j) Psychological Acts: These are the different emotions expressed through linguistic and extra-linguistic acts; see Acheoah (2015:23) for the diagram which shows concepts in the Pragma-crafting Theory.

\section{An InTEgrative Appraisal of SEARle's Theory}

I have used the term "integrative appraisal" to depict the two-fold theoretical underpinnings which this study employs; notions in Lawal's Communicative Model Theory and Acheoah's Pragma-crafting Theory give this investigation direction.

In (Sa), it is clear that Searle's theory captures the dynamics of human communication. Conventions of the language being used in a communicative event are explored by the participants of discourse for meaningful interaction. Without this, the inferential process will be problematic. Thus, speakers obey linguistic conventions intentionally; however, instances of violation of linguistic constants are interpreted via first-hand mastery of linguistic norms/conventions (referred to as "linguistic constants" in Lawal's Communicative Model Theory). For example, in the Nigerian speech community, the figure " 419 " has meanings which transcend its normative sense. Instead of meaning "number" or "figure", it means "a wide range of fraudulent acts". Hence, when a person is called a "419 person", the speech act performed is clear: it is an Ascriptive (See Bach and Harnish's (1979) speech act taxonomy to understand Ascriptives as speech act category) used by the encoder to condemn or insult his interlocutor. The perlocutionary act is therefore predictable; $\mathrm{H}$ (hearer) may react against $\mathrm{S}$ (speaker) in furious rage. It is of pragmatic relevance that a figure such as "419" implicates a wide range of societal 
phenomena - Acheoah (2015) opines that the term "Linguistic Implicatures (LIs) are meanings implied through language. Searle appears to have restricted his emphasis on the performance of linguistic acts in his discussion of speakers' intentions. I contend that fascinating, non-verbal acts are performed intentionally in discourse. Consider the conversation below taken from Ola Rotimi's Hopes of the Living Dead - I have numbered the utterances as U.1-U.9 for easy reference:

U.1 MATRON: With drumming and dancing! Where do you think

you are?

U.2 EDITOR: (With malevolent calm)

In the hospital. The General Hospital of his Imperial Majesty King George V

of England, situated in the land of Port Harcourt in the Colonial Territory of

Nigeria, West Africa, the World.

U.3 MATRON: Is that supposed to be plain rudeness, or a display of

high intellect in geography?

U.4 CAT: It's neither.

U.5 MATRON: Beg your pardon!

U.6 CAT: You asked a simple question and he gave you a simple answer.

U.7 MATRON: (curtly) No one is seeking your opinion. (turns again to Editor). In the first place, I was addressing him. (Indicates Nweke). Since when did you become the spokesman for the ... (restrains herself from describing group) or who do you think you are?

U.8 CAT: Another question.

U.9 EDITOR: Leper, madam. I am a leper like the rest ... of them (with a sweep of the arm taking in the entire inmates).Lepers, Lepers all at the mercy of the hospital authorities.

In the text, the extra-linguistic act of drumming is accompanied by lyrical music which conveys Behavioural Implicature; the act is wrong in the setting. Drumming and singing can take place in certain places, but not in a hospital. The encoder of U.2 engages in "crafting "to select appropriate linguistic "structures" and "structuring" that shows the extent of disgust he feels about the status-quo. This pragmatic selection and sequencing of communicative elements generates speaker-based sequel on the decoder who no doubt, is amazed at the sudden insubordination he suffers from his interlocutor. Indeed, the utterances (U.1-U.9) convey several pragmatic tools (notions in the Pragma-crafting Theory) because the participants are interactive ones. Non-interactive participants do not contribute to Communicative Features in Text. Characters in literary works use non-verbal means of amplifying verbal elements to register psychological contexts. It is obvious that U.2 is said with an extra-linguistic act (message-driven silence). Therefore, if the central and sub-themes in literary works are to be understood, all enacted dimensions of communication employed by the characters therein as chosen by the writers, have to be interpreted accordingly. This process of interpretation is facilitated by the fact that the characters (like extra-text participants of discourse) use speech acts according to conventional rules, context-driven rules (understood via various p-crafting features such as SMK, SCK, SKEC, BI, CP, the conventions of OL, etc.). 
The encoder of U.2 is calm, not because he is afraid or feels guilty that singing and drumming are done in a place meant for patients, but because he is gathering momentum to fight his interlocutor in words.

Searle contends that because speaking a language is performing acts according to rules, then "The semiotic structure of a language may be regarded as a conventional realization of a series of underlying constitutive rules. Part of the weaknesses of Searle's theory is that the concepts of "intention" and "convention" are loosely used. I hold the view that participants sometimes interpret communicative acts beyond their intended or conventional meanings. I am sure Searle aligns with my stance that in discourse, there are utterances that $\mathrm{H}$ cannot respond to, because the intention of $\mathrm{S}$ is either doubtful or not known. Consider the sentences below:

(i) There are no dogs in this house; it is open to all;

(ii) This is a friendly graveyard, so urinate here.

Through world knowledge, the decoder of the above sentences infers that the encoders of the utterances have bad intentions, but this interpretation may not be correct. Nevertheless, it is the duty of the encoder to convince the decoder that the utterances are not evil-intended. At times, communicative acts (verbal and non-verbal elements) have to be processed by the encoder so that the inferential process can be facilitated. Thus, conventional meanings of words that constitute utterances are not the basis for decoding illocutionary forces and perlocutionary acts. The loose use of the term "conventionality" remains part of the weaknesses of Searle's speech act theory. Unconventional use of verbal and non-verbal elements of communication appears conventional as a result of the contextual nuances which inform their use. No wonder Leech 1983:226) ponders on the verb "persuade" asking whether it must denote a linguistic act or a non-verbal act such as brandishing a hatchet. If linguistic and extra-linguistic acts may not be interpreted based on conventionality or intentionality, then their meanings can be processed by H. If (i) and (ii) above are mere inscriptions on a building, the decoder will doubt the writer's intentions despite their conventional meanings; in fact, their conventional meanings create more grounds (inferential process of "object referred" via mastery of the norms of the "operative language") for the decoder to doubt the writer. But if the encoder makes the decoder know what these expressions mean in the language in that particular speech community, the decoder will have no ground to interpret (i) and (ii) beyond the encoder's (writer's) intended meaning. For example, the writer (encoder) may make the reader (decoder) understand that "friendly graveyard" is another name for a public toilet: "friendly", because of its usefulness; "a graveyard", because people drop/"bury" waste products there. Consider the exchange below for more understanding of the fact that the conventional meanings of words have to be abandoned for pragmatic communication:

Student A: Why are you laughing?

Student B: I stole my book which was on the teacher's table.

Student A: $\quad$ Since it is yours, why did you say you stole it?

Student B: $\quad$ The teacher seized it from me and I took it without his knowledge and approval. 
From the conversation above, we can represent the semantics of the verb "stole" thus:

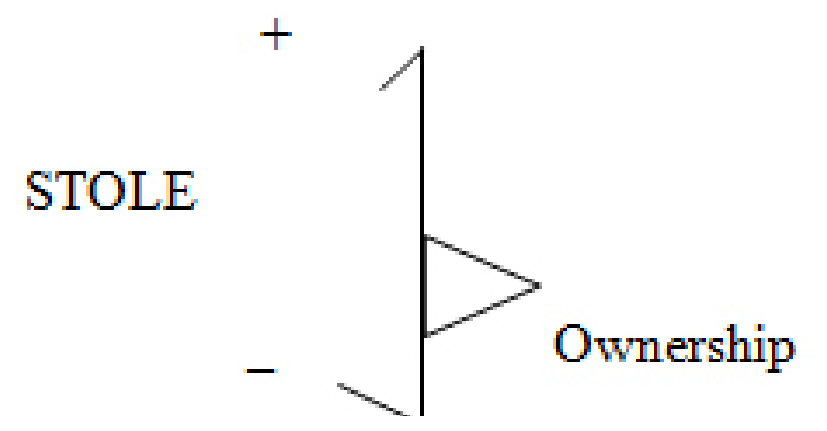

Fig1: The Pragma-semantics of the Verb "Stole"

In the figure above, "+" signifies that $\mathrm{S}$ owns the book (before it was seized), and "-" signifies that $\mathrm{S}$ does not own it if the teacher declares it so).

Speech act - as Searle contends in $(\mathrm{Sb})$ is the core of communication. Thus, speakers' intentions constitute the core of speech act theory. Halliday (1970) submits that "the particular form taken by the grammatical system of language is closely related to the social and personal needs that language is required to serve." Searle's stance on indirect speech acts is not elaborate enough to depict speech acts as the core of human communication. Due to the vibrant roles of indirect illocutionary strategies, any speech act theory (such as that of Searle) that is bereaved of their dynamics fail to position speech act phenomenon as the core of discourse. Indirect speech acts have great potentials in the analysis of human communication. In traditional speech act literature, they refer to utterances in which one says one thing and means another, or says one thing and means what he says and also means another illocution with a different propositional content. See Adegbija (1982:34) for critical perspectives on speech acts performed indirectly. Literary phenomena which writers find uneasy to communicate are communicated easily and clearly, using indirect speech acts, which are comprehended through inferential processes springing from mutually shared knowledge. The Pragma-crafting Theory establishes the link between general background knowledge and discrete inferential strategies in the process of working out meanings in discourse. Without speech acts, communication cannot take place. Perhaps, Searle himself acknowledges this by asserting that the performance of speech acts is the whole essence of communication.

Because words pick objects or ideas in the world, Searle evolves "words-to-world" direction-of-fit, whereas Allan (1986) evolves "world-spoken-of". Since literary works are products of the socio-cultural realities of their societies, one cannot interpret them without knowledge of their environmental and diachronic contexts. For example, in The Beautyful Ones Are Not Yet Born, Ayi Kwei Armah uses the expressions "Passion Week" and "half life of Passion Week" because the people in the speech community (physical setting of the novel) are familiar with the expression. The Pragma-crafting Theory uses the concept "Geoimplicatures" (restricted, regional meanings of utterances or expressions) to capture cross-cultural pragmatics. Acheoah (2011) coins the concept from "geographical" and "implicature" to refer to practices that have geographical restriction in terms of people, and not just in terms of physical boundaries. Such practices are not universal, and are either verbal or non-verbal. "Passion Week" is a period of the month in which workers still have enough money to spend. Therefore, "half-life of Passion Week" is "the period between the "easy" and the "difficult" moment - a period that survival is not so difficult, yet not so easy. Salary earners experience this trend. Nigerian literature has environmental contexts which shapes the way people in a particular speech community encode and decode messages in discourse. 
Searle's submission that whatever can be meant can be said - as in (Sc) - is logical and acceptable. The whole idea of pragmatics is to explain how it is possible for participants to communicate illocutionary goals, which invariably, are "meant intentions". Participants' ability to explore contextual variables (communicative competence) determines the extent that they can use language to say even the most abstract ideas in their minds. The emergence of pragmatics replaced "linguistic competence" with "communicative competence". Linguists who champion the cause of a context-dependent layer of linguistic study include: Austin (1962) and Lyons (1977). Discourse relies heavily on context for meaning. Consider the subtle illocutionary strategies employed by the encoder of the following utterance:

"The best selling books in town are: (i.) Value of Family Planning by 2face Idibia and (ii) Peaceful Co-existence by Boko Haram Sect.

The speech acts performed in (i) include: Informative, Descriptive, Disputative, Assertive, Declarative, Ascriptive and Dissentive. The illocutionary forces include: Informing, Condemning, Dissenting and Mocking. The perlocutionary acts are that the decoder is informed and amused. The decoders are aware that the famous Nigerian musician, 2face Idibia, has impregnated several ladies. He carries this stigma in the country, despite his feat in the musical industry. His name, as the text suggests, has become a usual collocate of "polygamy" or "womanizing". Against this background, the writer detaches from the readers' expectation; the readers' mindset and puzzle is: "Why should a polygamist be the author of a book which teaches the value of family planning?" The writer is consistent in using indirect illocutionary strategies to mean or refer to states-of-affairs. Within the context of family planning, the Object Referred (2face Idibia) is a deviant reference, therefore the readers presuppose (Contextual Presupposition) that the encoder is being indirect in the selection of Verbal Elements (VEs) of communication. There are three Contextual Objects that have been used as P-crafting Features (inference features) in (i) above: "value", "family-planning" and "2face Idibia". The decoders' uptake is that "the encoder is amusing the readers as well as mocking 2 face Idibia". Adegbija (ibid.) rightly notes that different contextual structures produce speech acts, and by this, he means that speech acts address issues in different domains of society. In establishing the relationship between the Master Speech Act and other speech acts in a given discourse, Adegbija contends that the pragmatic analyst should be able to: locate the contextual structure that produces the speech acts; investigate the thematic relevance of their selection and sequencing. The speech acts performed in (ii) are: Informative, Ascriptive, Dissentive, Descriptive, Assertive, and Disputative. The decoder is informed, amused and refreshed (perlocutionary act).

The objects referred: "peace" and "Boko Haram" are contradictory. The decoders are part of the social realism of Boko Haram's anti-peace posture and activities (Shared Macro-knowledge), so (ii) is decoded as thematic humour; any desire for peaceful co-existence cannot emanate from the Boko Haram sect who fight against the peace in society with unending passion. It is obvious that the encoder is from Nigeria where the Boko Haram Sect operates. First-hand knowledge of the linguistic conventions of OL facilitates the use of indirect speech acts to make reference to states-of affairs. The connections that discourse phenomena (speech acts, speaker-meaning, speakers' intention, hearers' uptake, conventions of the linguistic choices, etc.) have are rightly noted by Searle. Uptake was not hindered due to the common knowledge the participants have on the object referred. Lawal's views - that there is relationship between message and medium, and that in the performance of speech acts, ideas, beliefs, knowledge, feelings and attitudes of speakers are communicated - is profoundly acceptable. The encoder of U.1 epitomizes "colonialism" while the encoder of U.2 epitomizes "the colonized". Indeed, the colonial world is a two-fold world where the oppressors and the oppressed face one 
another with little hope of reconciliation. When literary works ponder on themes of oppression, language takes a violent dimension, and the stance of the oppressed is no longer that of a victim, but that of a resolute, mind, poised to confront oppressors and put an end to oppressive tendencies.

One of the strengths of Searle's theory is its portrayal of speech acts as acts that are not performed in a vacuum. His theory captures the idea that speech acts often have environmental contexts which determine the process of encoding and decoding them. The process of using speech acts to impinge on states-of-affairs inevitably engages dynamic, pragmatic instrumentalities such as implicatures and presuppositions. Linguistic Implicatures (LI) are potent in conveying messages when speech acts are engaged in spoken and written discourses. According to Levinson (1983:226), apart from speech acts, implicature and presupposition are among the central phenomena that any general pragmatic theory must account for. Indeed, linguistic choices and patterning are essentially the process of "crafting" towards achieving illocutionary goals.

The Pragma-crafting Theory contends that sociolinguistic variables determine implicatures and presuppositions in discourse. In making reference to societal phenomena, the indirect speech act potentials of speech act verbs are evident when such speech acts are used alongside other speech act categories in an utterance. To convey messages effectively, writers/speakers ensure that their selection and sequencing of speech acts are not incidental. Thus, the MESSAGE component in Lawal's Communicative Model Theory is all about the pragmatic interpretation of textual properties, even when indirect speech acts are articulated. It is logical to state that indirect illocutionary strategies are persuasive. Leech's view of style as "the dress of thought" makes it clear that the concern of persuasive speech (rhetoric) is the relationship between "what" is said and "how" it is said.

Searle's submission in (Sd) and Se draws attention to the fact that the violation of the Gricean Maxims creates implicatures in U.1-U.9; the turn-taking is questionable due to the psychological context. The linguistic behaviour of the interlocutors is influenced by the tense psychological atmosphere of the communication. Therefore, the term "Behavioural Implicature (BI) in the Pragma-crafting Theory is germane if African literature and human communication in general are to be understood. Adegbija (1982) notes that in textual analysis, while a synchronic perspective would be primarily concerned with the text per se, its present life, context and contemporary meaning, a diachronic perspective would introduce dimensions of meaning relating to the historical and global context enclosing a text. Such access to diachronic context is particularly relevant for a full elucidation of indirect speech acts. Diachronic contexts typically form central aspects of the mutually shared beliefs that are important for the understanding of linguistic, extra-linguistic and psychological acts performed when speech acts refer to states-of-affairs. The Pragma-crafting Theory is the product of a review of the loopholes in predating pragmatic theories. In the theory, two super-ordinate concepts: "Text" and "Events" - anchor a wide range of pragmatic notions which determine the use and interpretation of linguistic, extra-linguistic and psychological acts that are typical of natural communication.

Language use is a thing of credit. Selecting and sequencing speech acts is not just an act (mechanical process), but it is also an art (social competence is fused with the mechanical process of selecting the sequence of speech acts). The pragmatics of using language presupposes exploring situational or contextual variables. It is often the case that the encoder of an utterance presumes that his decoder has the cognitive maturity to make logical presumptions about utterances being that this decoder is part of the "world-spoken-of". Apart from making utterances worthy of inferences, encoders try to make such utterances easy-to mean. This process necessitates the use of world knowledge, implicatures and presuppositions. This is a way of ensuring that the fundamentals of communication theories are met. A speaker, despite his right to idiosyncratic use of utterances in discourse, 
should not make the inferential process of his utterances personal. A speaker's utterance is impersonal and meets the fundamentals of human communication if in saying $x$ in a particular same context to any member of that speech community, this speaker has meant $p$ to all members of that speech community.

Bronislaw and Archibald (2004) opine that there are usually constraints which inform the different components of speech. A speaker or writer does not merely use language to convey "social system", but also to influence it. Indeed, discourse analysis is not only language reflecting social order, but language shaping social order." David Harrah, cited in Savas (1994:375) posits: "Most speech acts seem to be focused and directed. They are intended as coming from the agent and going to the receivers or audience. They are intended to have a certain point, and they are intended to be construed as having a certain point." It is natural for participants of discourse to make utterances that have in-built contexts.

Searle's direction-of-fit and sincerity conditions potently depict the idea that crucial components of natural communication include: discourse relations, the force or strength with which an illocutionary force is performed and differences in the status of the participants.

I therefore align with Austin (ibid.) who contends that the pragmatic analyst should be interested in the total speech acts in the total speech situation". Fowler (1981:28) opines: "Linguistic structure is not arbitrary but is determined, or motivated, by the functions it performs." Searle's theory is worthy of scholarly attention. It is a classical theory which successfully shows that communication cannot take place unless at least two agents are actively involved. This submission is corroborated by (a)-(f).

\section{CONCLUSION}

This paper engages the pragmatic relevance and potency of Searle's speech act theory in the elucidation of the dynamics of natural communication. Pragmatic or speech act theories are theoretical underpinnings that abound (from classical to contemporary times) for the investigation of multi-facetted dimensions of human communication. Such dimensions are informed by the fact that sentence (utterance) meaning is a problematic pragmatic category. Savas L. Tsohatzidis (1994:1) rightly reports: “... in order to identify what a speaker means in uttering sentence of his language, it is not enough that you should know which individual he thereby purports to identify (for example, Mary), and which property he thereby purports to truly or falsely, ascribe to that individual (for example, the property of getting married to a linguist at some point in the future) - to put it more generally, it is not enough that you should know which proposition he purports to be expressing in uttering the sentence he utters. What is required, in addition, is that you should know what is the meaning-determining act in the context of which he expresses that proposition - whether, for example, he expresses it in the context of an act of giving permission, or in the context of an act of giving a question, or in the context of an act of making a prediction, or in the context of an act of raising an objection, and so on. These are some of the acts that, under the generic name of illocutionary acts that was given them by Austin (1962) constitute the primary subject matter of speech act theory."

The study of meaning presupposes the study of illocutionary acts. This view corroborates Savas (1994:.2) who posits that "knowing what illocutionary act a speaker has performed in uttering a sentence of his language is essential for knowing what he meant in uttering that sentence; it is well known, however, that what speakers of a natural language mean by uttering sentences of that language is not always the same as what those sentences themselves mean; given, then, that speaker meanings and sentence meanings can diverge, why should the study of illocutionary acts, essential though they may be in understanding speaker meaning, be deemed a 
necessary component of the study of linguistic meaning?" In a similar vein, Savas (1994:4) opines that "it is a logical possibility, of course, that, among the various components that presumably conspire in determining what speakers of natural languages mean, the illocutionary component should turn out to be relevant in specifying only what those speakers occasionally mean rather than what they standardly mean... if therefore, illocutionary acts are equally necessary in characterizing standard speaker meanings and occasional speaker meanings, the issues arising when one considers their role in these would be most profitably regarded as issues of semantic and of pragmatic theory respectively ${ }^{1 . "}$ Although the contributions of Searle's theory to the literature are epoch-making, this investigation finds that the theory is characterized by loose submissions on theoretical notions - this is one of the reasons why it cannot adequately account for certain dynamics of human communication

\section{Notes}

1. In this regard, Savas also notes that "unless one assumes (as no one assumes nowadays) that regularities in form are totally unconnected with regularities in meaning, no significant correlations of any sort between types of grammatical structure that utterances exemplify and types of illocutionary acts that they standardly perform; and if one did find such correlations, one might envisage to use them not only as the basis for a systematic description of the grammatical embodiment of semantically or pragmatically relevant distinctions, but also as a source of valuable insights concerning the nature of these descriptions. Consequently, the search for such correlations would not be devoid of theoretical interests (ibid. p.4)."

\section{REFERENCES}

Acheoah, J. E. (2011). “A Pragmatic Analysis of Ayi Kwei Armah's The Beautyful Ones Are Not Yet Born and Ola Rotimi's Hopes of the Living Dead."PhD Dissertation. Zaria, Ahmadu Bello University.

. (2014a). "The Illocutionary Frames Principle (IFP) and the Austinian Postulations: A Clause-structure Investigative Discourse." Global Journal of Human- Social Science, Linguistics and Psychology Volume 13, Issue 13, Version 1.0, pp. 21-29.

. (2015). "The Pragma-crafting Theory: A Proposed Theoretical Framework for Pragmatic Analysis." In International Journal of English and Literature, Volume 1, Issue 2:21-32, p.23.

Adegbija, E. F. (1982). "A Speech Act Analysis of Consumer Advertisements". USA: Indiana University. Ph.D Dissertation.

Allan, Keith. (1986). Linguistic Meaning Vols. I and II. London: Routledge and Kegan Paul. Ayi, Kwei Armah. (1968). The Beautiful Ones Are Not Yet Born. Great Britain: Cox and Wyman Ltd.

Austin, J. L. (1962). How to Do Things with Words. Cambridge: Harvard University Press.

Bach Kent and Harnish, Robert. (1979). Linguistic Communication and Speech Acts.

Cambridge: Massachusetts. The MIT Press.

Bronislaw M. (2004). "Language in Social Context" in O' Grady, William and Archibald John. eds. Contemporary Linguistic Analysis: An Introduction. Canada. Pearson Education.

Fowler, Roger. (1981). Literature as Social Discourse: The Practice of Linguistic Criticism. Bloomington: Indiana UP.

Halliday, M.A.K. (1970). "Language Structure and Language Function." In New Horizons in Linguistics. Ed. J. Lyons, Harmondsworth: Penguin. (pp. 140 - 165). 
Lawal, Adebayo (2012). "Aspects of a Stylistic Theory and the Implications for Practical Criticism." In Adebayo Lawal (ed.), Stylistics in Theory and Practice. Ilorin: Applied Linguistics Study Group (ALSG), University of Ilorin, p. 38.

Leech, G. (1983) Principles of Pragmatics. London: Longman.

Levinson, S. (1983). Pragmatics. Cambridge: Cambridge University Press. 1983, p.54.

Lyons, J. (1977). Semantics. Cambridge. Cambridge University Press. Rotimi, O. (1988). Hopes of the Living Dead. Ibadan: Spectrum in Association with Safari Books Limited: UK.

Savas, L. T. (1994). (Ed.). Foundations of Speech Acts Theory. London Routledge.

Searle, John. (1969). Speech Acts: An Essay in the Philosophy of Language. New York: Cambridge University Press.

Citation: Acheoah, John Emike, Searle's Speech Act Theory: An Integrative Appraisal. American Research Journal of English and Literature; Volume 3, 2017; pp:1-13

Copyright (c) 2017 Acheoah, John Emike. This is an open access article distributed under the Creative Commons Attribution License, which permits unrestricted use, distribution, and reproduction in any medium, provided the original work is properly cited. 